\title{
Protrusive Fracture Dislocation of the Hip with Preservation of Function
}

\author{
Amine Belmoubarik*, Nabil Omari, Reda Ghabri, Younes El Allali, Ahmed Reda Haddoun, \\ Mustapha Fadili, Mohamed Nechad
}

Service de Traumatologie Orthopédie Aile 4, Centre Hospitalier Universitaire Ibn Rochd, Casablanca, Maroc

Email: ${ }^{*}$ aminovich2005@gmail.com, nabilomari1983@hotmail.com, ghabrireda@gmail.com, allalialpha@gmail.com, m.fadili@gmail.com, redahaddoun@yahoo.fr, mohamednechad@gmail.com

Received 21 July 2015; accepted 9 August 2015; published 12 August 2015

Copyright (C) 2015 by authors and OALib.

This work is licensed under the Creative Commons Attribution International License (CC BY).

http://creativecommons.org/licenses/by/4.0/

(c) (i) Open Access

\section{Abstract}

The authors report a rare case of a young man of 20 who presented following an accident of the public highway a protrusive neglected fracture dislocation of the hip without impaired function. This is an observation describing frequent lesion entity in our context in the absence of major functional impact and the old character of the lesion. The abstention was the therapeutic adopted choice. We will discuss the mechanisms, our therapeutic attitude and evolution of this clinical entity through the analysis of this observation.

\section{Keywords}

Fracture Dislocation, Hip, Neglected, Conservation

Subject Areas: Orthopedics, Surgery \& Surgical Specialties

\section{Introduction}

Neglected fractures dislocations of the hip are relatively common in underdeveloped countries, pathology which progression to necrosis of the femoral head and/or hip osteoarthritis is marked even after introduction of surgical treatment. The authors report the case of a neglected hip fracture dislocation with good conservation of hip function.

\section{Observation}

Mr R.A. aged 20 years old, worker victim there a year ago, following a traffic accident, a fall with direct reception on hip at the origin of blunt trauma to the right hip. The patient had not consulted the emergency; he observed a

\footnotetext{
${ }^{*}$ Corresponding author.
}

How to cite this paper: Belmoubarik, A., Omari, N., Ghabri, R., El Allali, Y., Haddoun, A.R., Fadili, M. and Nechad, M. (2015) Protrusive Fracture Dislocation of the Hip with Preservation of Function. Open Access Library Journal, 2: e1770. 
bed rest for six weeks, with a self-rehabilitation. The evolution was marked by the gradual disappearance of pain and recovery subtotal of mobility. The patient presented after a year in consultation where noted limb shortening amounted to $2 \mathrm{~cm}$, a painless limp with preserved mobility of the hip in the different sectors. In radiographs to this decline, there was a central protrusive right hip fracture dislocation burglary of acetabular bottom back and shortening of cervical fracture without lever arm associated with the level of the femoral head necrosis or sequelar image with rise of $2 \mathrm{~cm}$ of the greater trochanter (Figure 1). A clinical examination and support bi monopodal (Figure 2 and Figure 3) possible, stable and painless, without pelvic tilt toward the traumatized hip demonstrating the absence of failure of diaper stay (sign Trendelenburg negative) (Figure 4). The walking is free not limited, the conserved passive mobility, active mobility reached $110^{\circ}$ in flexion, in extension $10^{\circ}$, internal rotation $70^{\circ}, 90^{\circ}$ external rotation, adduction $15^{\circ}$, abduction $60^{\circ}$. Muscle trophicity was preserved, as the motor and sensory examination and member of Vascular.

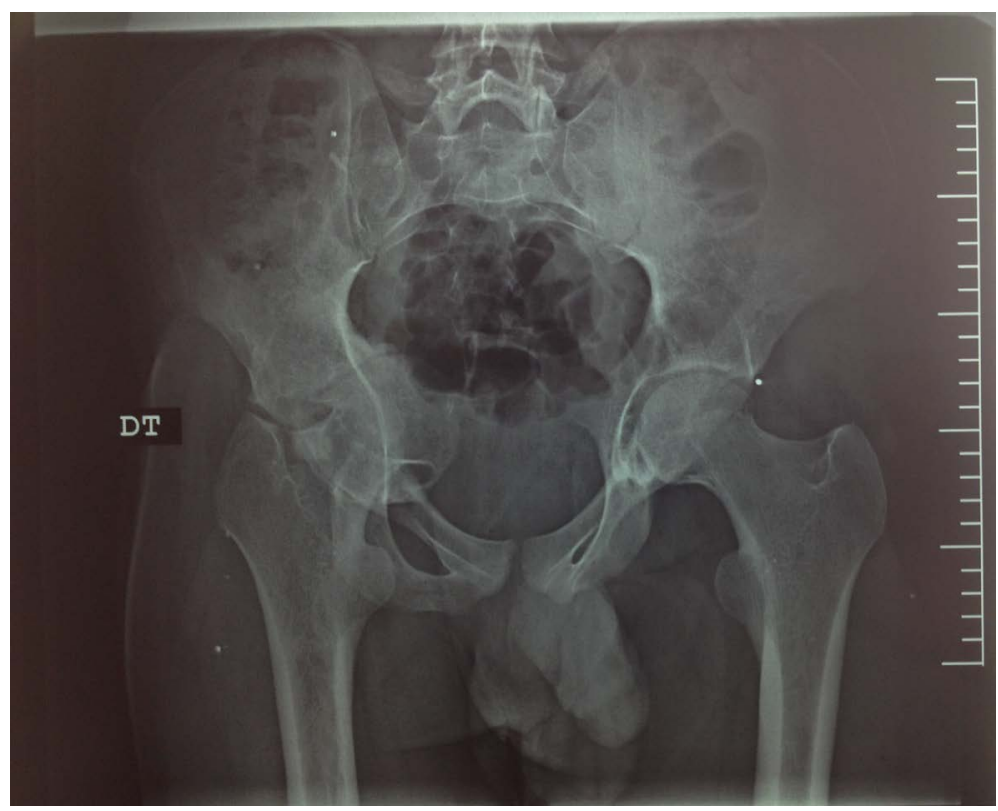

Figure 1. Basin opposite radiograph showing a central hip fracture dislocation.

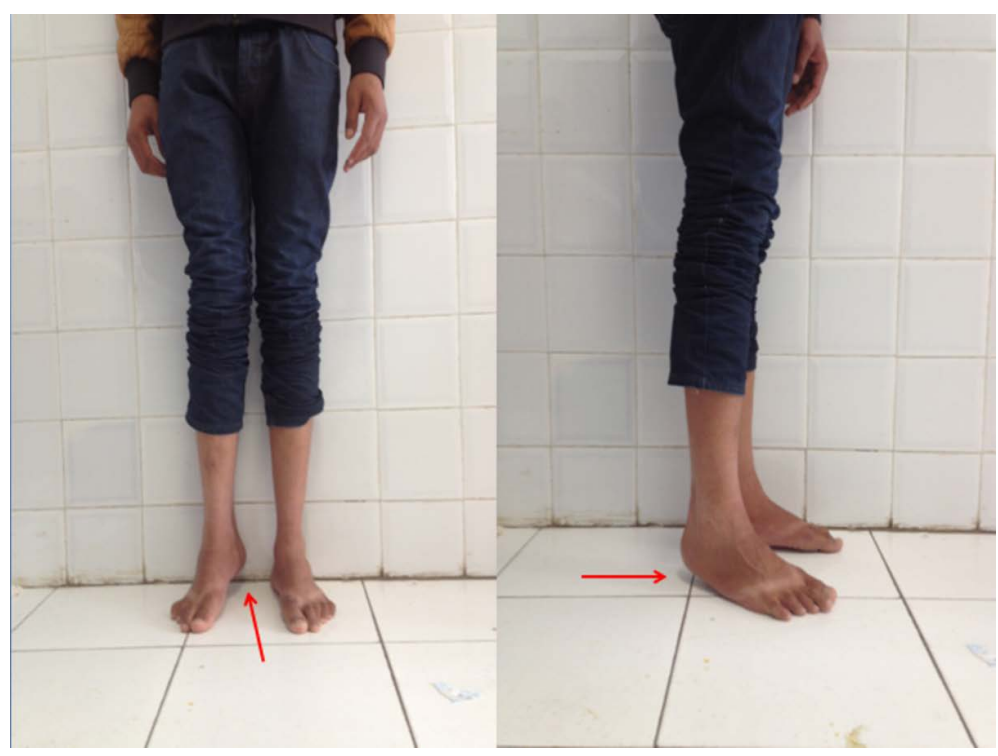

Figure 2. Image showing support bipodal saw the slight shortening of member front view and profile. 


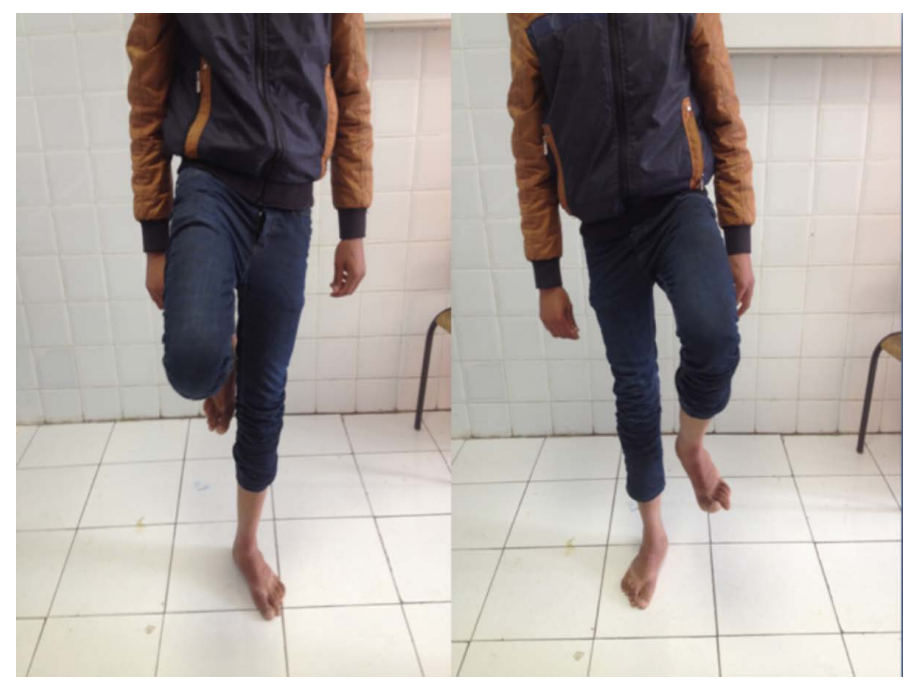

Figure 3. Image showing the possibility of the support monopodal.

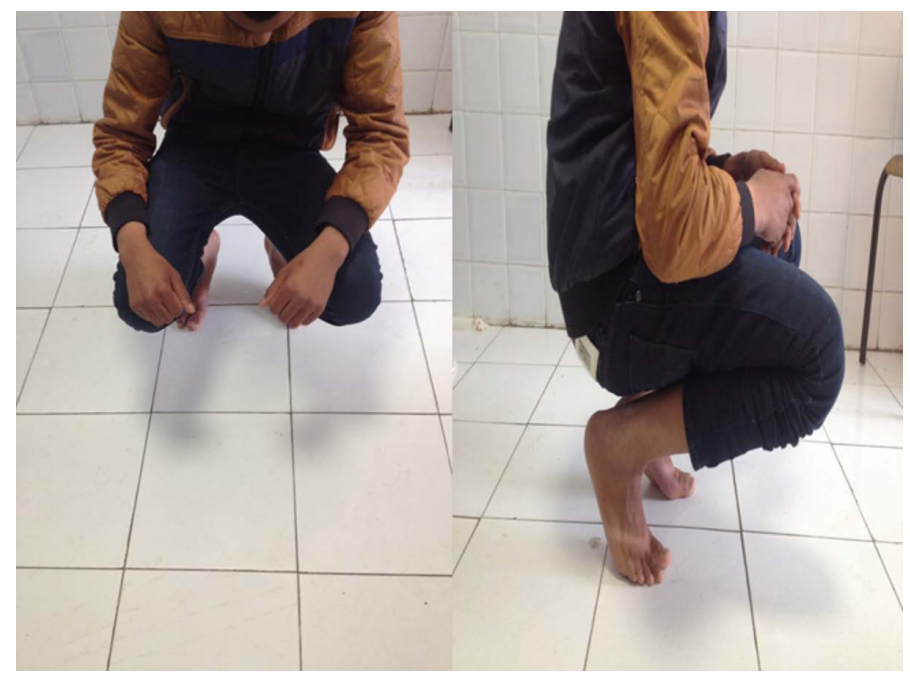

Figure 4. Image showing squatting front view and profile.

\section{Discussion}

The fracture-dislocation of the hip in his neglected form is a clinical entity that can still be seen in countries where health facilities have not yet reached their development; and is often attributed to a consultation delay on the part of the patient or diagnosis or incorrect or inadequate therapeutic indication. She is responsible usually a stiff hip or later of aseptic necrosis of the femoral head or hip osteoarthritis in the most advanced forms. Ameziane [1] dissociates fracture-dislocations of the hip on the time between the trauma brought the therapeutic procedure. Thus, an unreduced dislocation in the week expressed neglected; As for the acetabular fractures, it was from the third week. The management of neglected fracture dislocations of the hip is not unanimous in literature, it varies depending on the detection of stage one. Robin aubigné [2] [3], was among the first to report the results of their short experience of the condition and its treatment. The authors definitely refrain before a stiffness at the boundary of functional adaptation and can improve after a few weeks of rehabilitation. Some authors Mansouri [4] underlined the gravity of the functional impact on the hip dislocated in time without specifying the histological type. Jirari [5] shall not systematically neglected dislocations of the hip and emphasizes the difficulty encountered during the surgical approach because tissue remodeling and periarticular ossification. The bloody reduction remains frequent but not systematic indication. Several surgical techniques are reported in the literature ranging from the bloody reduction in hip arthrodesis through total joint arthroplasty. In our case, we 
have advocated no treatment for the age of the fracture dislocation on the one hand and the absence of major functional impairment other.

\section{Conclusion}

Fractures dislocations of the hip are common injuries, serious, often poorly tolerated and difficult to support. We emphasize the need to improve health facilities in the country to prevent this type of easy management of lesion if properly diagnosed and therefore urgently facilitate the installation of an appropriate therapeutic choice, without forgetting prevention accidents of public roads that are often responsible.

\section{Conflicts of Interest}

The authors declare no conflict of interest.

\section{Author Contributions}

All cited authors have contributed to the development of this work. All authors have read and approved the final manuscript.

\section{References}

[1] Ameziane, L., Hermas, M., El Yaacoubi, M., Ouazzani, N. and El Manouar, M. (1999) Les luxations et luxationsfractures négligées de la hanche. Médecine du Maghreb, 76.

[2] d'Aubigner, M. and Cotation, M.F. (1970) Chiffrée de la fonction de la hanche. Rev, Chir, Orthop, TOME, 56, 481486.

[3] d'Aubigne, M. and Mazas, R. (1963) Luxations postérieures traumatiques de la hanche. Ann Chir, 17, 1063-1090.

[4] Mansouri. Les luxations et fractures-luxations négligées de la hanche. Thèse de Médecine, RABAT No. $988,371$.

[5] Jirari, M. and Ismael, A. (1985) Les fractures-luxations de la hanche. Maroc Medical No. 1. 